\title{
THE RATIONAL DRUG USE OF DENTISTS IN A UNIVERSITY HOSPITAL
}

\author{
Abstract \\ Objective: To evaluate the status of receiving education on rational drug use, the criteria in \\ medical drug selection, and level of knowledge of dentists working in a dentistry faculty in \\ Turkey.
}

Material and Methods: This was a descriptive study based on a questionnaire. One hundred seventeen (74\%) dentists volunteered to participate in the study. The questionnaire consisted of 20 questions investigating sociodemographic features and rational drug use.

Results: The mean age of the dentists was $30.8 \pm 7.2$ years, and $62.4 \%$ were men. The mean period of professional experience was $8.9 \pm 7.1$ years. The most frequently used resources of references while prescribing medicine were Vademecum (medical drug guide) $(61.5 \%)$, the internet (59.0\%), and colleagues (49.6\%).

The most frequently reported condition described as 'good' was drug indications (43.6\%). The dentists had a moderate level of information about posology, and administration route $(48.7 \%)$, pharmacologic features (48.7\%), and contraindications (46.2\%). The number of dentists who stated that they considered cost while prescribing was low [always (6\%), and frequently $(15.4 \%)]$. Rational drug use education had been received by $23.9 \%$ of the dentists.

Conclusions: The dentists were found to have a lack of adequate and effective education on rational use of drugs. Regular and continuous education before and after graduation is a necessity for dentists and for their patients.

Key words: Dentist, Rational drug use, prescribe

\section{INTRODUCTION}

Medical drug treatment is the basic tool that physicians use to affect the health of their patients. These drugs may provide significant benefits for patients, but sometimes drugs may cause significant damage. There has been an increase in the numbers and diversity of drugs used in the treatment of the diseases in parallel with developments in medicine in the last century. Many factors such as the increased number of drugs, increased use of drugs, increased experience with the drugs, and the emergence of new treatment regimens necessitate that physicians and physician candidates behave rationally in the use of drugs. The irrational or inappropriate use of drugs might give harm to patients, increase the use of unnecessary and/or expensive drugs, and might cause problems such as antibiotic resistance and ineffective treatments [1-4]. 
The World Health Organization (WHO) describes rational drug use (RDU) as "the use of drugs appropriate for the clinical requirements of the patients, in appropriate doses, for adequate time, with the lowest cost to the patient, and to the society"[1]. The WHO organizes various activities and makes recommendations for extending the practices of rational drug use. The establishment of an organization for controlling the policies of medical drug use, preparing lists of frequently used drugs, preparation of guidelines, the inclusion of additional courses in medical education on RDU, giving importance to continuous medical education, educating the public on the use of medical drugs, and controlling the expenses for drugs are the practices of the WHO [2].

Dentists prescribe various drugs specific for their area in addition to general medical drugs. In dentistry, antibiotics are typically prescribed as therapy for dental, oral, and maxillofacial infections, as prophylaxis against focal infections in patients at risk (endocarditis and joint prostheses), and as prophylaxis against local infection and systemic spread in oral surgery [5]. Studies conducted in the United Kingdom (UK) reported that 9-10\% of all antimicrobial drugs were prescribed by dentists 4. It was identified in many studies on prescribing medicine that the appropriate prescribing of antibiotics was a significant problem in dentistry facilities. It was stated that the most important cause of this problem generally stemmed from not complying with the available treatment guidelines [6]. There was a tendency of prescribing analgesics in addition to antibiotics among dentists because infection mainly caused pain [7-9].

In particular, choosing rational antibiotics and analgesics constitute two critical topics for dentists. There are a relatively high number of national and international resources on the rational use of antibiotics that might be beneficial for dentists [10]. The necessity of appropriate education on RDU in medical treatment of patients, particularly in drug selection, and the continuity of such education were emphasized in many studies performed with dentists in various countries such as the UK, Sweden, Belgium, and Pakistan [9, 11-13]. In the present study, we aimed to evaluate the education status on the use of rational drugs, the selection criteria for drugs, and the level of knowledge of dentists working in a dentistry faculty in Turkey.

\section{METHODS}

The was a descriptive study based on a questionnaire. A total of 158 individuals including research asistants $(n=57)$, doctoral students $(n=35)$, and academics $(n=66)$ working in the Dentistry Faculty in Ondokuz Mayıs University were included in the study. Local ethics board approval was granted for the study (OMU-KAEK 2016/152). There was no sampple 
selection, this was a volunteer-based study. The questionnaire on RDU used in this study, which is open for general use, was prepared by the Turkish Ministry of Health (The Evaluation Study on the Knowledge and Behaviors of Physicians Working in Hospitals in Turkey). There were a total of 20 questions about sociodemographic features and on the rational drug. Dentists were visited in their working environment in the hospital and were informed about the study. Questionnaires were delivered to dentists who volunteered to participate in the study, and were collected within the same day. A total of 117 (74.0\%) dentists consisting of 56 (47.9\%) residents, $42(35.9 \%)$ academics, and 19 (16.2\%) doctoral students volunteered to participate in the study.

The results of the questionnaire were evaluated using the Statistical Package for the Social Sciences (SPSS) 22.0 package program. The descriptive statistics of the data were identified as number $(\%)$ and standard deviation (SD). The Shapiro-Wilk test was used to investigate the appropriateness of measurable values to normal distribution in statistical comparisons. The Mann-Whitney U test was used to compare the means of the two groups, and the Chi-square test was used to compare the frequency of data. Statistical significance was accepted as $\mathrm{p}<0.05$ for all tests.

\section{RESULTS}

The mean age of the dentists was $30.8 \pm 7.2$ years, and $73(62.4 \%)$ were men. The mean period of professional experience was $8.9 \pm 7.1$ ( $\min : 2$, max: 30$)$ years. The mean time for examination for each patient was $34.7 \pm 16.8$ (min: 10, max: 120) minutes, and the mean number of medical

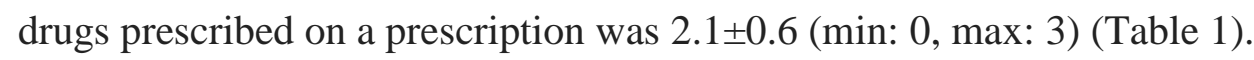

The most frequently used resources of dentists while prescribing were detected as Vademecum (medical drug guideline) (61.5\%), the internet (59.0\%), colleagues (49.6\%), pharmacology books (13.7), representatives of drug companies (10.3\%), diagnosis and treatment guidelines (8.5\%), Turkish Medical Treatment Guidelines (7.7\%), and drug information software programs (e.g., Rx MediaPharma, TEBRP) (1.7\%), respectively. Some multiple choice answers were available. The rate of dentists who stated that "I do not use any information resource" was $11.1 \%(\mathrm{n}=13)$.

The evaluation of the responses of dentists to the question 'What do you think about your level of knowledge of drugs? showed that the most frequently responded condition as 'good' was 'drug indications' (43.6\%). Dentists most frequently responded 'moderate' regarding their level of knowledge of 'posology, and administration route' (48.7\%), 'pharmacologic features' (48.7), contraindications $(46.2 \%)$, and 'warnings, precautions' $(44.4 \%)$. The number of dentists who 
stated that their level of knowledge of drugs on different areas as 'very good' or 'very bad' was significantly low (Table 2).

Safety (68.4\%), efficacy (62.4\%), and appropriateness $(60.7 \%)$ were found to be the criteria the dentists 'always' considered in accordance with the responses of dentists to the question, 'Which criteria do you consider while selecting drugs in prescriptions?' However, it was striking to observe that $40.2 \%$ and $38.4 \%$ of the dentists stated that they 'sometimes' or 'never' considered the cost of drug, respectively (Table 3).

Twenty-eight (23.9\%) of the participants reported that they received education on RDU during their dentistry education. The mean age and professional experience of dentists who

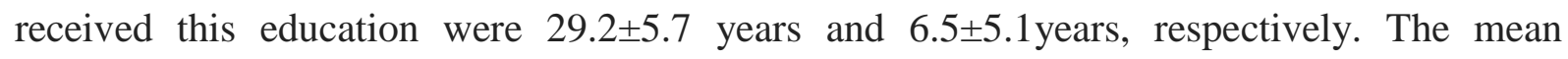
examination time of the same group was $36.6 \pm 23.5 \mathrm{~min} /$ per patient, and the mean number of prescribed drugs was $2.1 \pm 0.65$ (per patient). There was no statistically significant difference regarding age, professional experience, examination time, and the mean number of prescribed drugs between dentists who did and did not receive RDU education. In addition, the comparison of the 'level of knowledge about drugs' and 'the criteria considered in selecting the drug' of dentists who received RDU education, and who received no RDU education showed no statistically significant difference $(\mathrm{p}>0.05)$.

\section{DISCUSSION}

Dental prescriptions provide short-term treatment or treatment specifically for surgical procedures; nevertheless, dentists require knowledge about drugs and must follow the international rules for prescribing. There is evidence in studies that dentists generally lacked appropriate pharmacologic information, and therefore they sometimes made prescription errors [7, 14-15]. In addition to the pharmacologic information in dentistry faculty education, the sources of information used while prescribing drugs in professional life play a significant role in the selection of drugs [16]. Although there are small number of studies on the sources of information that dentists used while prescribing drugs, a wide range of information resources (e.g., Vademecum, the internet, colleagues) was identified in the comparisons in our study. However, it was evaluated that the use of resources recommended in the selection of rational drugs such as 'Guidelines for Diagnosis and Treatment' and the 'Turkish Medical Treatment Guidelines' (7.7\%) was inadequate. In addition, it should be born in mind that the accuracy and reliability of drug information obtained from the internet and colleagues must be approached with suspicion. Students of dentistry in Mexico and India were reported to benefit from their professors at university as the source of information (44\% and $36 \%$, respectively). The use of the "WHO Guide to Good Prescribing" of these students was reported to be $30 \%$ in Mexico, 
and only 9\% in India [7-8]. The most frequently used information resources of dentists were reported to be the Monthly Index of Medical Specialties (MIMS) (32\%), medical representatives (MRs) (28\%), and the internet (19\%) in the study of Sharma [17]. Dentists must be attentive in the use of MRs as sources of information. The frequency of the use of MRs of dental drug companies as sources of information was $51 \%$ in one study, and $40 \%$ among general physicians in another study, both of which were higher compared with the dentists in our study (10\%) [18-19]. Rational drug prescription is described as the use of the minimum drug to obtain the best possible effect in the shortest period with a reasonable cost [8]. However, studies have shown that MRs of drug companies were frequently used as information resources when prescribing drugs, and this resulted with polypharmacy, reduced the quality of prescriptions, and greatly increased the cost of treatment [20-21].

The appropriate prescription of medication should "maximize efficacy and safety, minimize cost, and respect patient's preferences." Choosing the most appropriate medication for each patient in order to achieve desired therapeutic outcomes is a challenge for healthcare professionals in their daily practice [22]. The 'WHO Guide to Good Prescribing' recommends the systematic evaluation of drugs for efficacy, safety, appropriateness, and cost in selecting drugs for specific conditions [23]. This study reported that dentists 'always' and 'frequently' considered the other criteria; however, it was striking to observe the high rates of responses of 'sometimes' or 'never' in considering drug cost (40\% and 38\%, respectively). 'Efficacy' was considered as important in the selection of drug in a study by more than $90 \%$ of general practitioners; however, 'drug cost' was considered important by only 50\% [19]. Although drug selection is performed appropriately with the other criteria, the disregard of cost means 'irrational drug practice' and this is particularly observed in the selection of antibiotics among dentists $[13,24]$. The selection of more expensive drugs rather than using cheaper generic drugs significantly increases treatment costs and causes an additional burden to the health economy and for the country, which is unfortunately observed more frequently in developing countries $[6,25]$.

Dentists must be aware of the accurate doses and interactions of frequently used antibiotics, anti-inflammatory analgesics, and local anesthesia used in dental procedures, and they must be aware of any negative or toxic effects of the drugs [8]. In the present study, the dentists reported having inadequate or moderate levels of knowledge on various topics, particularly on posology, adverse effects, pharmacologic features, drug interactions, and bioequivalence when they were questioned on their level of knowledge on the features of drugs. In a study that investigated the prescription errors of students of dentistry, $74 \%$ of the students 
were found to have inadequate information on drug posology [7]. The lack of information on these topics may give harm to patients as a consequence of irrational drug prescribing. In the last few years, medication errors have been reported to have caused significant patient harm in many countries. In the United States of America, it is estimated that 1-2\% of hospital admissions resulted from medication errors. In Spain, medication errors were responsible for $4.7 \%$ of admissions to health services, with an average cost of 3000 EUR per patient [3, 2627]. Although medical drug prescribing errors are well-documented in the literature, publications on the prescription errors of dentists are rare, and more studies are required. The primary causes of prescription errors of dentists were observed as unnecessary or multiple drug prescriptions due to difficulties in defining the problem of the patient, a lack of information about the current prescription drugs of the patient, and the limited education on RDU of dentists [15].

It was stated that education on RDU was given in approximately $70 \%$ of medical faculties in Turkey by academics in pharmacology departments as the education curriculum permitted [28]. However, there is inadequate information about dentistry faculties where RDU education is provided in Turkey. We found that only $23.9 \%$ of dentists working as research assistants, doctoral students, and academics who graduated from different faculties in Turkey received education on RDU. The number of dentists who receive such education is suggested to be inadequate.

One of the limitations of the study is that the period of RDU education, the education content, and from where the dentists received information were not questioned. However, the detection of no difference regarding the drug information, and other factors between the dentists who did and did not receive education suggests that the period and content of RDU education is inadequate. Heaton et al. reported in their questionnaire study with 25 students and new graduates of a medical faculty in the UK that only RDU education was inadequate for the effective and safe drug use of $74 \%$ of the participants. Conversely, the results of systematic collections showed that the frequency of unnecessary antibiotic prescription decreased, and success was reported in increasing the compliance with national guidelines after education on antibiotic prescribing when RDU was provided for general practitioners and dentists [29-31]. Similarly, an increase was detected in some skills such as drug prescription and informing the patient after RDU education in a study with dentists in Turkey [18].

We suggest that education on RDU, especially of frequently used drugs such as antibiotics, anti-inflammatory analgesics, and local anesthetics is required for dentists. Regular education before and after graduation, and continuity of education will be beneficial for the 
permanency of information. In addition, supporting this education with practice is suggested to increase the rate of treatment success by providing convenience in the daily professional lives of the dentists.

Author Contributions: Conceptualization, O.T. and F.Y.; Methodology, , O.T. and F.Y.; Software, O.T..; Validation, , O.T. and F.Y.; Formal Analysis, O.T.; Investigation, O.T.; Resources, F.Y.; Data Curation, F.Y.; Writing - Original Draft Preparation, , O.T. and F.Y.; Writing - Review \& Editing, O.T.; Supervision, O.T.

Funding: None

Acknowledgments: None

Conflicts of Interest: The authors declare no conflict of interest.

\section{REFERANCES}

1. World Health Organization. Promoting Rational Use of Medicines: Core Components-WHO Policy Perspectives on Medicines. WHO; 2002 [cited 201631 May].

2. World Health Organization. The world health report 2002: reducing risks, promoting healthy life: WHO; 2002.

3. Bates DW, Spell N, Cullen DJ, Burdick E, Laird N, Petersen LA, Small SD, Sweitzer BJ, Leape LL. The costs of adverse drug events in hospitalized patients. JAMA. 1997;277(4):307-11.

4. Cope AL, Chestnutt IG. Inappropriate prescribing of antibiotics in primary dental care: reasons and resolutions. PDJ. 2014;3(4):33-7.

5. Hamoudi NM, Fuoad SA, Aziz Z, Saddeq M. Antibiotic utilization pattern in dental practice in Ajman, UAE: a prospective study. J Advanced Scientific Research (JASR). 2013;4(3):17-20.

6. Fadare JO, Oshikoya KA, Obimakinde OS, Sijuade AO, Afolayan JM, Adeleke AA, Godman B, Ojumu DO. Patterns of drugs prescribed for dental outpatients in Nigeria: findings and implications. Acta Odontol Scand. 2017;75(7):496-506.

7. Guzmán-Álvarez R, Medeiros M, Lagunes LR, Campos-Sepúlveda A. Knowledge of drug prescription in dentistry students. Drug Health Patient Saf. 2012;4:55.

8. Jain A, Gupta D, Singh D, Garg Y, et al. Knowledge regarding prescription of drugs among dental students: A descriptive study. J Basic Clin Pharm. 2015;7(1):12.

9. Ellervall E, Björklund F, Rohlin M, Vinge E, Knutsson K. Antibiotic prophylaxis in oral health care: administration strategies of general dental practitioners. Acta Odontol Scand. 2005;63(6):321-9.

10. Akici A, Gocmen G. Rational Pharmacotherapy Management Process in Dentistry. Marmara Pharmaceutical Journal. 2017;21(3):436-44.

11. Palmer N, Martin M, Pealing R, et al. Antibiotic prescribing knowledge of National Health Service general dental practitioners in England and Scotland. JAC. 2001;47(2):233-7.

12. Mainjot A, D'hoore W, Vanheusden A, et al. Antibiotic prescribing in dental practice in Belgium. Int Endod J. 2009;42(12):1112-7.

13. Tanwir F, Marrone G, Lundborg CS. Knowledge and reported practice of antibiotic prescription by dentists for common oral problems. J Coll Physicians Surg Pak. 2013;23(4):276-81.

14. Cherry WR, Lee JY, Shugars DA, White Jr RP, Vann Jr W F. Antibiotic use for treating dental infections in children: A survey of dentists' prescribing practices. $J$ Am Dent Assoc. 2012;143(1):31-8.

15. Mendonça JM, Lyra DP, Rabelo JS, et al. Analysis and detection of dental prescribing errors at primary health care units in Brazil. Pharm World Sci. 2010;32(1):30.

16. Le Grand A, Hogerzeil HV, Haaijer-Ruskamp FM. Intervention research in rational use of drugs: a review. Health policy Plan. 1999; 14(2):89-102.

17. Sharma K, Sharma A, Singh V, Pilania D, Sharma YK. Irrational fixed dose combinations \& need for intervention: understanding of dental clinicians and residents. JCDR. 2014;8(12):ZC49.

18. Öcek Z, Sahin H, Baksi G, Apaydin S. Development of a rational antibiotic usage course for dentists. Eur J Dent Educ. 2008; 12(1):41-7. 
19. Theodorou M, Tsiantou V, Pavlakis A, et al. Factors influencing prescribing behaviour of physicians in Greece and Cyprus: results from a questionnaire based survey. BMC Health Serv Res. 2009;9(1):150.

20. de Bakker DH, Coffie DS, Heerdink ER, van Dijk L, Groenewegen PP. Determinants of the range of drugs prescribed in general practice: a cross-sectional analysis. BMC Health Serv Res. 2007;7(1):132.

21. Spurling GK, Mansfield PR, Montgomery BD, Lexchin J, Doust J, Othman N, Vitry AI. Information from pharmaceutical companies and the quality, quantity, and cost of physicians' prescribing: a systematic review. PLoS Med. 2010;7(10):e1000352.

22. Kaufmann CP, Tremp R, Hersberger KE, Lampert ML. Inappropriate prescribing: a systematic overview of published assessment tools. Eur J Clin Pharmacol. 2014;70(1):1-11.

23. Ross S, Loke YK. Do educational interventions improve prescribing by medical students and junior doctors? A systematic review. Br J Clin Pharmacol. 2009;67(6):662-70.

24. Al-Harthi SE, Khan LM, Abed HH, Alkreathy HM, Ali AS. Appraisal of antimicrobial prescribing practices of governmental and non-governmental dentists for hospitals in the western region of Saudi Arabia. Saudi Med J. 2013;34(12):1262-9.

25. Al-Haroni M, Skaug N. Knowledge of prescribing antimicrobials among Yemeni general dentists. Acta Odontol Scand. 2006;64(5):274-80.

26. Kohn LT. The Institute of Medicine report on medical error: overview and implications for pharmacy. Am J Health Syst Pharm. 2001;58(1):63-6.

27. Otero López MJ. Errores de medicación y gestión de riesgos. Rev Esp Salud Publica. 2003;77:527-40.

28. Akici A, Gelal A, Erenmemisoglu A, et al. Examining the state of the pharmacology department in rational drug use education in medical school application process in Turkey. TEJ. 2011;29(29):1120.

29. Roque F, Herdeiro MT, Soares S, Rodrigues AT, Breitenfeld L, FigueirasA. Educational interventions to improve prescription and dispensing of antibiotics: a systematic review. BMC public health 2014, 14 (1), 1276. .

30. Löffler C, Böhmer F. The effect of interventions aiming to optimise the prescription of antibiotics in dental care-A systematic review. PloS One. 2017;12(11):e0188061.

31. Heaton A, Webb DJ, Maxwell SR. Undergraduate preparation for prescribing: the views of 2413 UK medical students and recent graduates. Br J Clin Pharmacol. 2008;66(1):128-34.

Table1. Some features of the dentists

\begin{tabular}{|l|l|l|}
\hline Variable & Value \\
\hline $\begin{array}{l}\text { Gender } \\
\mathrm{n}(\%)\end{array}$ & Female & $44(37.6)^{*}$ \\
\cline { 2 - 3 } $\begin{array}{l}\text { Position } \\
\mathrm{n}(\%)\end{array}$ & asistans & $73(62.4)^{*}$ \\
\cline { 2 - 3 } & doctoral students & $56(47.9)^{*}$ \\
\cline { 2 - 3 } & academics & $19(16.2)^{*}$ \\
\hline Age (year) & $32(35.9)^{*}$ \\
\hline $\begin{array}{l}\text { Working time } \\
\text { (year) }\end{array}$ & $1-5$ & $70.8 \pm 7.2$ \\
\cline { 2 - 3 } & $6-10$ & $17(14.5)$ \\
\hline $\begin{array}{l}\text { Examination time } \\
\text { (per patient) (minute) }\end{array}$ & $30(25.6)$ \\
\hline $\begin{array}{l}\text { The mean of prescribed drugs } \\
\text { (per patient) }\end{array}$ & $\begin{array}{l}34.7 \pm 16.8 \\
(\min : 10-\text { max:120 ) }\end{array}$ \\
\hline
\end{tabular}

* column percentage 
Table 2. The distribution of the responses of dentists to the question, 'What do you think about your level of knowledge of medical drugs.'

\begin{tabular}{|l|l|l|l|l|l|}
\hline & Very good & Good & Average & Bad & Very bad \\
\hline İndications & 6.8 & 43.6 & 38.5 & 8,5 & 2,6 \\
\hline $\begin{array}{l}\text { Posology and method of } \\
\text { drug application }\end{array}$ & 2,6 & 24,8 & 48,7 & 19,7 & 4,2 \\
\hline $\begin{array}{l}\text { Pharmacological } \\
\text { properties }\end{array}$ & 0,9 & 18,8 & 48,7 & 24,8 & 6,8 \\
\hline Contraindications & 2,6 & 27,4 & 46,2 & 19,7 & 4,1 \\
\hline Side effects & 0,9 & 20,5 & 41,0 & 33,3 & 4,3 \\
\hline $\begin{array}{l}\text { Drug Interactions (another } \\
\text { drug/food) }\end{array}$ & 0,0 & 13,7 & 40,2 & 40,2 & 5,9 \\
\hline Warnings, Precautions & 0,9 & 29,1 & 44,4 & 18,8 & 6,8 \\
\hline $\begin{array}{l}\text { Exceptions (pregnancy, } \\
\text { child ie.) }\end{array}$ & 5,1 & 34,2 & 41,9 & 15,4 & 3,4 \\
\hline Bioequivalence & 0,0 & 10,3 & 42,7 & 38,5 & 6,8 \\
\hline
\end{tabular}

Table 3. Distribution of criteria that dentists take into account in drug selection

\begin{tabular}{|l|l|l|l|l|l|}
\hline & Always & Often & Sometimes & Never/seldom & Total \\
\hline Efficacy & 62,4 & 32,5 & 2,6 & 2,5 & 100,0 \\
\hline Safety & 68,4 & 26,5 & 2,6 & 2,5 & 100,0 \\
\hline Appropriateness & 60,7 & 29,9 & 3,4 & 6,0 & 100,0 \\
\hline Cost & 6,0 & 15,4 & 40,2 & 38,4 & 100,0 \\
\hline
\end{tabular}

